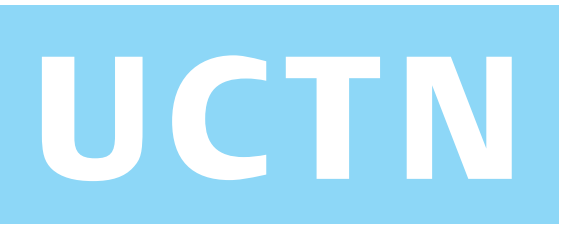

\title{
Endoscopic treatment of completely occluding anastomotic web using incision and ballooning after dye injection
}

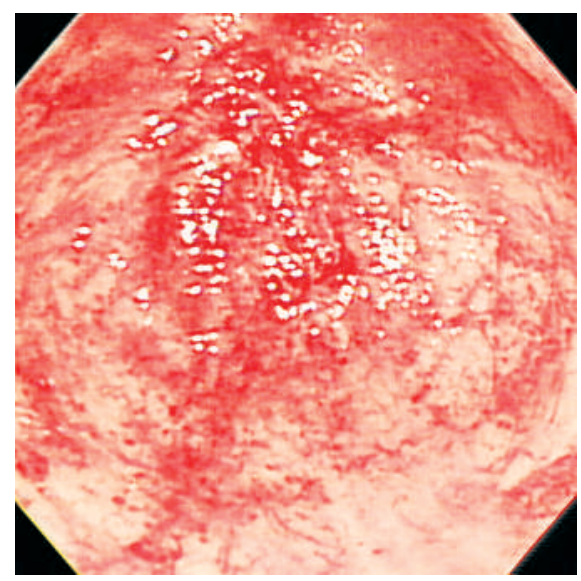

Figure 1 Appearance of a completely occluding web at the level of the anastomosis, $8 \mathrm{~cm}$ from the anal verge.

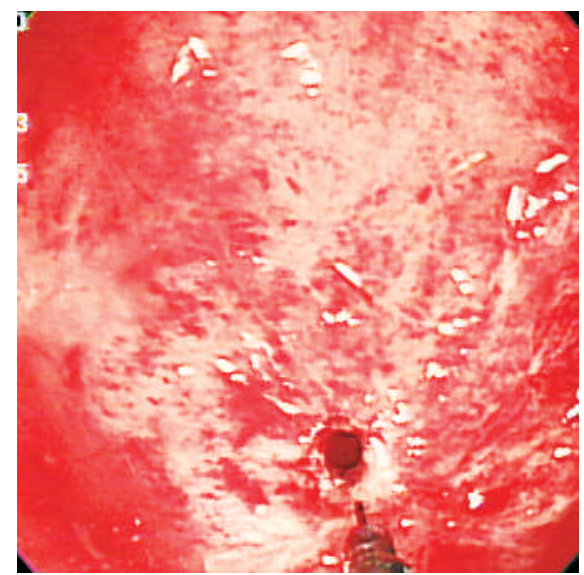

Figure 4 Rupture of the anastomotic occlusive web using a needle-knife at the site of injection.

A 73-year-old woman with rectal adenocarcinoma at $10 \mathrm{~cm}$ from the anal verge underwent laparoscopy-assisted low anterior resection with a protective loop ileostomy. Postoperatively the patient received adjuvant radiotherapy and chemotherapy for 6 months. After the chemoradiation treatments, a digital rectal examination prior to ileostomy takedown revealed anastomotic obstruction. Under direct visualization using a colonoscope (CF-Q240; Olympus Optical Co, Ltd, Japan), no opening was found in the anastomotic occlusive web (Figure 1). Fluoroscopy showed a blind end at the level of the anastomosis (Figure 2). An injector (NM-

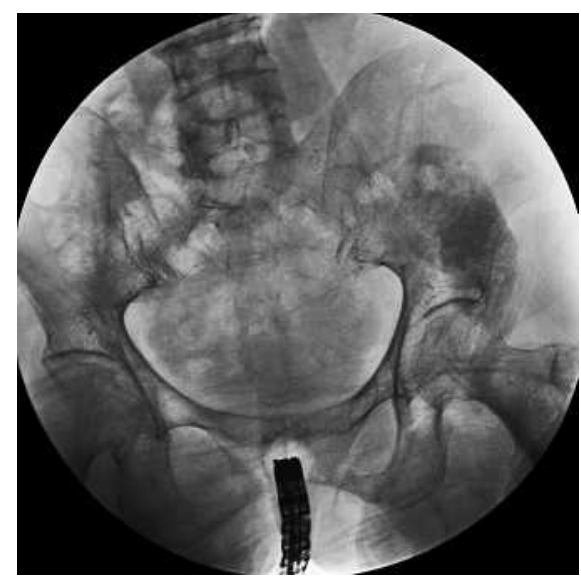

Figure 2 Fluoroscopy showing a blind end at the level of the anastomosis.

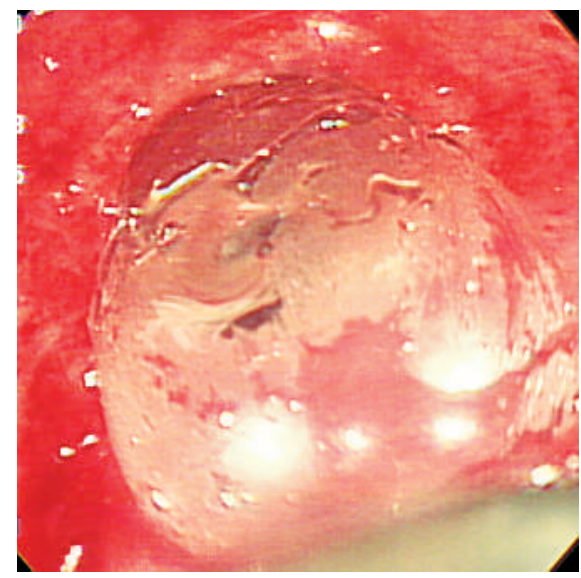

Figure 5 Water insufflation of the "through the scope" hydrostatic balloon dilation at the level of the anastomosis.

200U; Olympus) was inserted into the center of the circular staple line at the level of the anastomosis, and diluted dye (Telebrix; Guerbet, France) was injected to identify the proximal lumen under fluoroscopic guidance (Figure 3). Injection of water through the injector dilated the lumen of the proximal atrophied bowel. The anastomotic occlusive web was incised in a radial fashion using a needlepapillotome (MTW Endoskopie, Germany) (Figure 4). Under endoscopic observation, a controlled radial expansion balloon dilator (Boston Scientific Cork Ltd, Ireland) was inserted through the web opening and insufflated with water (Figure 5).

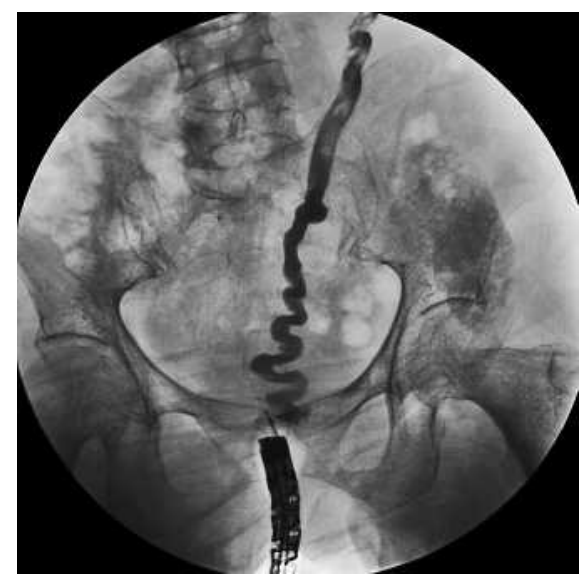

Figure 3 Fluoroscopic identification of the proximal bowel after dye injection at the center of the circular staple line.

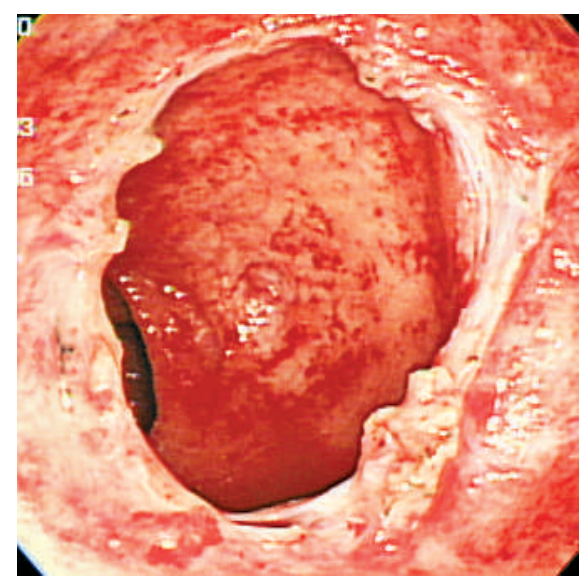

Figure 6 Complete destruction of the occlusive web after balloon dilation and restoration of bowel lumen.

The successful destruction of the occlusive web facilitated passage of the colonoscope, allowing evaluation of the entire colon (Figure 6). The patient tolerated the procedure well without complications.

Management of anastomotic strictures is mainly performed endoscopically by balloon dilation $[1-3]$. Patients with a completely occluding anastomotic web lack even a small opening through which a guide wire can be inserted, making further major corrective surgery technically demanding. In one patient, a completely

DOI: $10.1055 / s-2006-945145$ 
obstructed colonic anastomosis was managed using a combined antegrade-retrograde endoscopic rendezvous technique using two colonoscopes [4]. With our endoscopic technique, injection of a dye under fluoroscopic guidance enabled us to identify the proximal lumen and to rupture the occlusive web successfully.

Endoscopy_UCTN_Code_TTT_1AQ_2AF

J. W. Park, D. K. Sohn, K. S. Han, C. W. Hong, H. J. Chang, K. H. Jung, D. Y. Kim, S.-B. Lim, H. S. Choi, S.-Y. Jeong Center for Colorectal Cancer, Research Institute and Hospital, National Cancer Center, Goyang, Korea.
References

${ }^{1}$ Truong S, Willis S, Schumpelick V. Endoscopic therapy of benign anastomotic strictures of the colorectum by electroincision and balloon dilatation. Endoscopy 1997; 29: $845-849$

2 Picon AI, Guillem JG. Anastomotic occlusive web following double-stapled anterior resection and fecal diversion. Presentation and endoscopic management. Surg Endosc 1998; 12: $156-158$

${ }^{3}$ Suchan KL, Muldner A, Manegold BC. Endoscopic treatment of postoperative colorectal anastomotic strictures. Surg Endosc 2003; 17: $1110-1113$

${ }^{4}$ Kaushik N, Rubin J, McGrath K. Treatment of benign complete colonic anastomotic obstruction by using an endoscopic rendezvous technique. Gastrointest Endosc 2006; 63: $727-730$
Corresponding author

\section{K. Sohn, MD}

Center for Colorectal Cancer Research Institute and Hospital National Cancer Center 809 Madu-dong Ilsan-gu, Goyang Gyeonggi 411-769

Korea

Fax: $\quad+82-31-9200002$

Email: gsgsbal@ncc.re.kr 